\title{
Factors Affecting Indonesian Pre-Service Teachers' Use of m-LMS: A Mix Method Study
}

\author{
https://doi.org/10.3991/ijim.v14i06.12035 \\ Aman, Lantip Diat Prasojo, \\ Universitas Negeri Yogyakarta, Yogyakarta, Indonesia \\ Muhammad Sofwan, Amirul Mukminin, Akhmad Habibi ${ }^{(凶)}$, \\ Universitas Jambi, Jambi, Indonesia \\ akhmad.habibieunja.ac.id \\ Lalu Nurul Yaqin \\ Universitas Gunung Rinjani, West Nusa Tenggara, Indonesia
}

\begin{abstract}
The purpose of this research is to investigate factors affecting Indonesian pre-service teachers' (PSTs) teachers' use of m-learning management systems (m-LMS) in higher education. The difference regarding the use of m-LMS based on some demographic information namely gender, university, year in university, and age are also reported as well as gaining an indepth understanding of the use of m-LMS in Indonesian universities. To achieve this, two approaches, quantitative and qualitative, were applied. First, we developed and distributed a survey instrument to 210 PSTs in history education based on the technology acceptance model (TAM). In addition, we interviewed 7 of them to obtain an in-depth understanding of the use of mlearning in their learning. Some statistical calculations were presented such as mean, standard deviation, Cronbach's alpha, t-test, and ANOVA. Findings suggest that PSTs' use m-LMS are related to their perceived usefulness and perceived ease of use, subjective norm and attitudes self-efficacy and supporting condition. From these results, we suggest that teacher educators target these factors within teacher development training programs in preparing PSTs for successful integration of m-LMS.
\end{abstract}

Keywords-M-LMS, PSTs, learning, TAM

\section{Introduction}

M-learning is a trend in educational technology enabling a rapid change in learning because of the fast development of mobile technologies [1]. M-learning is defined as a new kind of learning that is encouraged by mobile devices that include the current technology of communication and data sharing [2]. The trend of m-learning helps students enjoy a personal-customized learning on mobile devices. Recently, many new mobile services have been integrated into mobile technologies into educational systems [2]. 
As m-learning evolves, the establishment of applications that can be integrated with mobile devices including the m-learning system (m-LMS) is widely-used [3]. The m-LMS are defined as a way of m-learning tools providing faculty and student an online platform to courses regardless of time and location. Even though m-LMS facilitate tools for PSTs to link with their mobile devices for learning, limited studies were conducted regarding factors affecting the use of m-LMS, especially in developing countries.

Facilitating university students with m-LMS does not automatically address the actual use. They possibly have various perceptions of the system. Therefore, this study was conducted to investigate factors affecting Indonesian PSTs' use of mlearning in higher education. It also aimed to inform the difference regarding the use of m-LMS based on gender, university, year in university, and age. To support the survey data, we interviewed 7 PSTs to gain an in-depth understanding of the use of mLMS in Indonesian universities. We chose Indonesia since this developing country is one of the most users of mobile devices with high rate of mobile devices penetration.

\section{Literature Review}

\subsection{Theories of technology adoption}

Some frameworks have been established to examine users' intention to use and actual use of new technologies in education such as the Technology Acceptance Model (TAM) [4], theory of planned behavior [5], and innovation diffusion theory [6]. Among the proposed models, TAM has become became a very important model to understand factors predicting human behavior on potential technology acceptance [7]. TAM has its focus on the perceived usefulness and perceived ease of use. It was originally examined the use of technology in some domains of economic business and proved to become reliable to predict such as online shopping [8] or e-commerce [9].

\subsection{Technology adoption in educational settings}

Even though TAM originally aimed to explain technology adoption by users in economics, it has been further use as an investigation tool for educational purposes $[10,11]$. Among several previous studies which have applied TAM or its extended model in adoption of technology in education, many researchers have focused on the adoption of mobile learning in teaching or learning processes [12] and learning management systems [10]. However, the researches facilitate the readers with insights understanding into the factors that may affect the adoption of m-LMS [13, 14]. Moreover, not many of them informed the use of TAM in a descriptive way or reported differences based on demographic information regarding the use of m-LMS in education as well as exhibited qualitative analysis on the TAM application measuring the adoption m-LMS in education. 


\subsection{Adoption of $\mathrm{m}$-LMS in higher education}

Even though many previous studies applied TAM to examine the adoption of elearning and mobile learning; few studies were conducted to examine the adoption of $\mathrm{m}$-LMS in higher education. M-LMS which is defined as a software application to set administration, documenting, tracking, reporting, and addressing educational courses and training programs $[13,14]$. The learning management system is established directly from e-Learning. The m-LMS in this study are Moodle to Edmodo which used by PSTs in two Indonesian universities.

\section{$3 \quad$ Method}

In this study, we informed the descriptive statistics of a survey investigating factors affecting Indonesian PSTs' use of m-LMS in higher education. We also informed the difference regarding the use of m-LMS based on some demographic information namely gender, university, year in university, and age. To support the survey data, we interviewed 7 PSTs to gain an in-depth understanding of the use of m-LMS in Indonesian universities.

\subsection{Instrumentation}

Quantitatively, the instrument for the survey includes two sections. Part 1 consists of a nominal scale to recognize respondents' demographic information. Meanwhile, part 2 aims to examine respondents' factors affecting the use of m-LMS. The part 2 instrument was modified from the original scales of TAM [4] and other relevant studies $[12,13]$. To make sure that the instrument fits the setting of m-LMS, changes in wordings were made for the easiness of the instrument's interpretation and understanding. Three experts of educational technologies were involved in the discussion as part of content validity in developing the instrument [15]. The instrument was translated involving two sworn translators from English to Indonesian and from Indonesian to English which is also called back translation [16]. To strengthen its validity, the survey instrument was pre-tested to 73 PSTs. The analysis of the pre-test or pilot test was conducted through factor analysis and Cronbach's alpha. From the results, 21 indicators were listed for the main data collection. A 7point Likert scale, with 1 being the lowest score (strongly disagree) and 7 being the highest (strongly agree), was used to examine respondents' responses.

In the qualitative approach, semi-structured interview questions were developed. Experts in areas of educational technology were invited to discuss the questions first draft to establish the validity [17]. Questions for the interview of the PSTs included 10 items established from the analysis results of the quantitative data. Because the interviews were semi-structured based on the analysis of the quantitative phase and conversational in nature, the wording could be different from one interview to the other interviews, but all respondents were requested to have responses to similar 
topics. The questions were translated into Indonesian discussed by the two sworn translators.

\subsection{Sampling and data collection}

An online survey instrument was shared with PSTs in history education in two public universities in Indonesian from Mei to July 2019. We masked the names of the university to become University 1 and University 2 as part of the research ethic. To determine the sample of the survey, we used $* \mathrm{G}$ power that results in minimal numbers of 127 respondents for 6 variables involved in this study. However, we managed to obtain 210 measurable responses (100 males and 110 females). 144 respondents are from University 1 and 66 respondents from University 2. Besides, 74 respondents' ages are from 17 to 19 years old while 50 respondents are from 19 to 22 years old and 86 of them are above 22 years old. From the year in university, 66 PSTs are 1 st year students, 86 respondents in the 2 nd year, 40 respondents in the 3 rd year, and 18 respondents in the 4 th year.

Convenience sampling is considered an appropriate method for the descriptive mix method [16]. We chose it by asking the survey respondents who were willing to participate in the interview sessions. Finally, seven participants agreed to participate in this study by filling in the form in the survey questionnaire. They were invited through phone calls and personal messages to attend the interview. Using a smartphone as the recording tool, the interview was conducted in an office room of one of the two universities. We reward the interviewees for their willingness to attend the interview.

\subsection{Data analysis}

The data that was collected through Google form was transferred to Microsoft excel. The preparation was done by assessing outliers, missing data, and histograms [18]. As the data has been through the process of screening, the analysis was conducted by calculating Mean and Standard deviation for the descriptive analysis. Cronbach's alpha was used to understand the reliability of each variable. Further, ttest, and ANOVA were applied to measure the difference between demographic information regarding the use of m-LMS. SPSS 23 was used for the qualitative data analysis.

In the qualitative phase, the researcher analyzed the data by using within- and across-case analysis [16]. Within-case analysis in qualitative culture is a deep exploration of a case, as a stand-alone object including attachment to a certain case with a particular case to know how the processes happened and revealed in that study meanwhile cross-case analysis is used or implemented in a study as the analysis is a case. We manually transcribed the data and compiled the typed transcription. We read and re-read the transcripts in order to highlight and examine for connections and redundancies using Microsoft word's review feature. The coding process was further done for the highlighted texts through Macros as the coding tool attached in Microsoft word [19]. To establish the trustworthiness of the study, triangulation, member 
checking, and reflexivity to strengthen the trustworthiness were taken to ensure the trustworthiness of the data collected $[16,20]$.

\section{$4 \quad$ Findings}

\subsection{Quantitative}

In elaborating on the results of the study, descriptive statistics in terms of mean (M), standard deviation (SD), and Cronbach's alpha are reported. As seen in Table1 of this study, all variables and indicators have means of above 5 which can be defined as satisfactory which the measurement of the Likert scale range from 1 (strongly disagree) to 7 (strongly agree) attitudes gained the highest mean $(\mathrm{M}=5.495 ; \mathrm{SD}=$ .999). Meanwhile, the lowest variable mean is the use of $\mathrm{m}-\mathrm{LMS}(\mathrm{M}=5.137 ; \mathrm{SD}=$ 1.062). As per indicator, AT 1 obtains the highest mean $(\mathrm{M}=5.571 ; \mathrm{SD}=1.156)$ while the lowest means is informed for USE $2(\mathrm{M}=5.105$; $\mathrm{SD}=1.213)$. The Cronbach's alpha values of the final results of the analysis also exceed the threshold value of .70 in which the values range from .874 to .925 . The complete report of the statistical descriptive values is shown in Table 1 below.

Table 1. Mean, SD, and Cronbach's alpha

\begin{tabular}{|c|c|c|c|c|c|c|}
\hline Variables & $\mathbf{M}$ & SD & $\alpha$ & Indicators & $\mathbf{M}$ & SD \\
\hline \multirow[t]{3}{*}{ Perceived usefulness } & 5.416 & 1.006 & .889 & PU1 & 5.314 & 1.185 \\
\hline & & & & PU2 & 5.495 & 1.055 \\
\hline & & & & PU3 & 5.438 & 1.097 \\
\hline \multirow[t]{3}{*}{ Perceived ease of use } & 5.263 & 1.092 & .912 & PEU1 & 5.362 & 1.116 \\
\hline & & & & PEU2 & 5.238 & 1.120 \\
\hline & & & & PEU3 & 5.191 & 1.306 \\
\hline \multirow[t]{3}{*}{ Subjective norm } & 5.349 & 1.042 & .904 & SN1 & 5.391 & 1.210 \\
\hline & & & & $\mathrm{SN} 2$ & 5.267 & 1.109 \\
\hline & & & & SN3 & 5.391 & 1.094 \\
\hline \multirow[t]{3}{*}{ Attitudes } & 5.495 & .999 & .888 & AT1 & 5.571 & 1.156 \\
\hline & & & & AT2 & 5.448 & 1.071 \\
\hline & & & & AT3 & 5.467 & 1.090 \\
\hline \multirow[t]{3}{*}{ Supporting condition } & 5.425 & .983 & .865 & $\mathrm{SC} 1$ & 5.391 & 1.049 \\
\hline & & & & $\mathrm{SC} 2$ & 5.438 & 1.089 \\
\hline & & & & $\mathrm{SC} 3$ & 5.448 & 1.182 \\
\hline \multirow[t]{3}{*}{ Self-efficacy } & 5.349 & 1.029 & .925 & SE1 & 5.438 & 1.062 \\
\hline & & & & SE2 & 5.314 & 1.092 \\
\hline & & & & SE3 & 5.295 & 1.157 \\
\hline \multirow[t]{3}{*}{ Use of m-LMS } & 5.137 & 1.062 & .874 & USE1 & 5.133 & 1.268 \\
\hline & & & & USE2 & 5.105 & 1.213 \\
\hline & & & & USE3 & 5.171 & 1.076 \\
\hline
\end{tabular}

Besides the descriptive statistics reports, the current study also informs whether the demographic information (gender, university, age, and year in university) differs in 
regard to the use of m-LMS. The t-test was used to examine the difference of the use of m-LMS in terms of gender and university while ANOVA was applied to assess the difference regarding years in university and age. Table 2 shows the results of the t-test informing that a significant difference emerges in regard to the use of m-LMS in terms of gender $(t=2.595 ; \mathrm{p}<.05)$. However, no significant differences is found for the use of $\mathrm{m}-\mathrm{LMS}$ based on the university $(\mathrm{t}=1.593 ; \mathrm{p}>.05)$. The ANOVA test exhibits that no significant difference is found based on years in university $(\mathrm{F}=.995$; $\mathrm{p}>.005)$ in relation to the use of m-LMS. However, a significant difference emerged based on age $(F=13.846 ; p>.005)$.

\subsection{Qualitative}

Perceived usefulness and perceived ease of use: The interview results reinforced the survey findings. The codes in the interview data were merged to establish three themes for perceived usefulness and perceived ease of use: Value for effective learning and easy to use but difficult to integrate within lessons.

Value for effective learning: The interview informed that the improvement of students' learning was the most frequently cited reason to use m-LMS. All 7 interviewees mentioned that they used m-LMS in their learning due to its benefits. They perceived the use of m-LMS as a suporting way to communicate in the classroom and to have them be more involved into varied learning experiences and extended time for learning. For instance, one of the PSTs had her comment,

" $\mathrm{m}$-LMS enhances learning by facilitating some types of learning

opportunities for us. We can utilize m-LMS to link with friends and

lecturers outside the classroom and to have other learning environments into the classroom."

Similarly, another PST stated in the interview that she thinks that m-LMS is a great way to build communication in the classroom and have students more involved. They also highlighted that m-LMS technologies are appropriate tools to help explain learning concepts better and cater to the needs of different learning styles they have. For instance, one of the interviewees mentioned that m-LMS can visually elaborate concepts which would be good for them because they tend to be more visual learners.

Easy to use: Almost all $(\mathrm{n}=7)$ of the PSTs felt that m-LMS are easy to operate. They also informed that technology can better the efficiency of their work.

"I am more than open to using the technology in my learning because

these technologies let things be easier and it can save our time in learning, a very efficient way to learn."

Difficult to integrate within lessons: Although the PSTs felt very confident using $\mathrm{m}$-LMS technologies, they believed that it requires more effort for their lecturers or professors to come up with new ideas that have been already available. Most of them believed that it might be challenging for them. One of the PSTs stated that he ever once proposed to his lecturers that a new fresh idea should be implemented for the use of m-LMS in their lectures so that it can decrease the feeling of "bored" for the repeating tasks in the m-LMS. 
Subjective norm and attitudes: Two themes associated with subjective norm and attitudes found in the analysis of the interview data: Need to meet the needs of digital age and expectations of lecturers and peers.

Need to meet the needs of the digital age: During the interviews, the influence exerted emerged as an important consideration among the PSTs when describing their use of m-LMS into their learning. All PSTs consider that the ways in learning are influenced by the use of m-LMS they use,

"I hope more lecturers will use the m-LMS in their teaching. It is very important for us as millennials to get more engaged in technology especially

mobile learning. It is expected more applications are utilized in our department."

Most of the interviewees $(n=5)$ thought that using m-LMS technologies will enable them to be more connected to their peers in the current digital age. One of the participants informed that in the digital age the use of m-LMS or mobile learning cannot be avoided since this could make people more connected.

Expectations of lecturers and peers: The participants indicated that their use of mLMS is influenced by their lecturers and peers when talking about people's influence on the use of mobile learning in their education. Six of the 7 interviewees believe that their lecturers always expect them to use the technology; one of the interviewees had her opinion,

"I think that lecturers who are encouraging more m-LMS technology to

be used in our courses can be very influential because it is more interesting and helps us learn creatively."

All PSTs felt that their peers' successes with the use of m-LMS in learning to influence their action to use m-LMS. As one of the PSTs stated in the interview that if his peers did well in learning using m-LMS. So he would also use m-LMS in a maximal way.

Self-efficacy and supporting condition: Two themes associated with self-efficacy and supporting conditions emerged from our analysis of data: High self-efficacy for $\mathrm{m}$-LMS and anytime/anywhere access to m-LMS.

High self-efficacy for $m$-LMS: The interview data informed that all participants felt very comfortable using m-LMS. Therefore, they have high self-efficacy for the use of $\mathrm{m}$-LMS in their learning.

"In general, m-LMS technologies are easy to use. I have a very high selfefficacy in using m-LMS in my learning."

When discussing their skills and knowledge about mobile technology, the participants mentioned that they are skilled in finding the right applications in their smartphone and have the ability on their use. One of the interviewees said that as a millennial, she had no problems in using mobile phone application including m-LMS. She continued that she was very confidence if her lecturers assigned her to use mLMS in her learning.

Anytime/anywhere access to m-LMS: The data reported that PSTs perceived mLMS as useful because of easy and quick access inside and outside of the classroom. Most of the participants believed that m-LMS address them more resources which are 
even accessible from outside the classroom as long as they have their smartphone in their hand.

"Using m-LMS allows us to access lessons from anywhere. As long as we have access to the internet and we have our smartphone, we can access the m-LMS from any place."

Many applications in m-LMS would help them learn more effectively. Moreover, some of the PSTs believed that due to the accessibility of m-LMS, the technologies could broaden PSTs' knowledge and provide interaction by sharing ideas with other people. Generally, the participants of the interview seemed to have great motivation in using $\mathrm{m}$-LMS for their learning because they have increased interaction, information, and resource accesses.

\section{Discussion}

The purpose of this research is to investigate factors affecting Indonesian PSTs' use of m-LMS in higher education. The difference regarding the use of m-LMS based on some demographic information namely gender, university, year in university, and age are also reported. To support the survey data, 7 PSTs were interviewed to gain an in-depth understanding of the use of m-LMS in Indonesian universities.

The findings of the survey inform that the average perception of the students of the TAM factors is moderate that is understood from the mean of each indicator. The quantitative analysis also reports that a significant difference is found in regard to the use of m-LMS based on gender and age. The data analysis of this mix method study revealed that Indonesian PSTs in the two universities believed that the adoption of mLMS technologies into learning in higher education is very beneficial and has improved their learning. This perceived usefulness of m-LMS technologies was encouraged by the value of m-LMS technology for improving the engagement, communication, and improving the overall learning experiences by incorporating innovative learning tools to which students can have the relationship. These results are similar to that of [13] who noted that m-LMS increases engagement in learning among students because they can be used to develop creativity and critical thinking collaboratively.

Besides, the PSTs in this study believed that m-LMS are very easy to use. As millennials, they use technology especially mobile devices on a daily basis that make the tools to be their daily friends. Some of them even acknowledge that they cannot live without their gadgets. This finding corroborates [14] findings that PSTs found $\mathrm{m}$ LMS easy to use for their own personal needs. These results suggest that m-LMS can create a more engaging environment for PSTs in learning in higher education due to their familiarity with mobile devices.

The PSTs in this study also perceived that the adoption of m-LMS is influenced by their lecturers and peers as part of the subjective norm in the TAM framework. These findings could be comprehended as the influences of the culture of the east that always respect other people and therefore they are always influenced by other peoples' actions. Indonesian tend to respect other people's opinions and have a 
tendency to imitate what other people do, including for the PSTs in learning with mLMS [7]

The reports of this study inform that the PSTs are encouraged to use m-LMS technologies due to their high self-efficacy perception regarding their knowledge and ability to have these technologies used inside and outside classrooms. One certain possible cause for these findings might focus on the fact that the participants in our study involve every day with their gadgets on a daily basis. This belief echoes previous studies' results informing m-LMS self-efficacy as a positive influence on students' use of m-LMS in higher [14]. Besides high self-efficacy, PSTs in this study also believe that learning through m-LMS can be referred to anytime and anywhere access to the technology and become a positive influence on their use of m-LMS in learning. They believed that possessing easy access to more information, resources, and tools not only facilitate motivation to use the technology inside the classroom but will also facilitate them to use the technology outside the classroom.

\section{Conclusion}

The results indicate that the PSTs' use of m-LMS technologies in history education is affected by perceived usefulness, perceived ease of use, subjective norm, attitudes, supporting condition, and self-efficacy. The findings recommend that teacher education programs should always provide encouragement to make these factors promoted to better prepare PSTs in learning using m-LMS technologies and also use the m-LMS for their future careers as future teachers. Teacher educators or lecturers should target PSTs' beliefs on the values of these technologies in learning and teaching. Providing PSTs more opportunities to use m-LMS reflect on the pedagogical implications of m-LMS technology integration can have a positive influence on their use of m-LMS in their daily learning and their future careers. Success in this term may need the implementation of some progressive steps for the teacher education experience, for instance, to support beliefs progressing about positive use in m-LMS learning. Future studies should determine the specific interventions that align with PSTs' perceived usefulness, perceived ease of use, subjective norm, attitudes, supporting condition, and self-efficacy to help teacher education programs develop a better preparation for their PSTs to integrate m-LMS in higher education. Besides, longitudinal researches may be planned to determine if these perceptions about using m-LMS. A complex statistical analysis such as structural equation modeling should also be an option.

\section{$7 \quad$ Acknowledgement}

This research is co funded by Universitas Negeri Yogyakarta and Universitas Jambi. 


\section{References}

[1] Han, I., \& Shin, W. S. (2016). The use of a mobile learning management system and academic achievement of online students. Computers \& Education, 102, 79-89. https://doi. org/10.1016/j.compedu.2016.07.003

[2] Gao, S., Krogstie, J., \& Siau, K. (2014). Adoption of mobile information services: An empirical study. Mobile Information Systems, 10, 147-171. https://doi.org/10.1155/2014/ $\underline{146435}$

[3] Brantes Ferreira, J., Zanela Klein, A., Freitas, A., \& Schlemmer, E. (2013). Mobile learning: definition, uses and challenges. In Increasing student engagement and retention using mobile applications: Smartphones, Skype and texting technologies (pp. 47-82). Emerald Group Publishing Limited. https://doi.org/10.1108/s2044-9968(2013)000006d005

[4] Davis, F. D. (1989). Perceived usefulness, perceived ease of use and user acceptance of information technology. MIS Quarterly, 13, 319-340. https://doi.org/10.2307/249008

[5] Ajzen, I. (1991). The theory of planned behavior. Organizational Behavior and Human Decision Processes, 50, 179-211. https://doi.org/10.1016/0749-5978(91)90020-t

[6] Rogers, E. M. (1995). The diffusion of innovations. New York: Free Press.

[7] Muhaimin, Habibi, A., Mukminin, A., Pratama, R., Asrial, \& Harja, H. (2019). Predicting factors affecting intention to use web 2.0 in learning: Evidence from science education. Journal of Baltic Science Education, 18(4), 595-606. https://doi.org/10.33225/jb $\underline{\mathrm{se} / 19.18 .595}$

[8] Gefen, D. (2003). TAM or just plain habit: A look at experienced online shoppers. Journal of End User Computing, 15, 1-13. https://doi.org/10.4018/9781591402572.ch001

[9] Pavlou, P. A. (2003). Consumer acceptance of electronic commerce: Integrating trust and risk with the technology acceptance model. International Journal of Electronic Commerce, 7, 101-134. https://doi.org/10.1080/10864415.2003.11044275

[10] Alharbi, S., \& Drew, S. (2014). Using the technology acceptance model in understanding academics' behavioural intention to use learning management systems. International Journal of Advanced Computer Science and Applications, 5, 143-155. https://doi.org/10. $\underline{14569 / \text { ijacsa.2014.050120 }}$

[11] Hsu, H.-H., \& Chang, Y. Y. (2013). Extended TAM model: Impacts of convenience on acceptance and use of Moodle. US-China Education Review, 3, 211-218.

[12] Park, S. Y., Nam, M. W., \& Cha, S. B. (2012). University students' behavioral intention to use mobile learning: Evaluating the technology acceptance model. British Journal of Educational Technology, 43: 592-605. https://doi.org/10.1111/j.1467-8535.2011.01229.x

[13] Iqbal, S., \& Bhatti, Z. A. (2017). What drives m-learning? An empirical investigation of university student perceptions in Pakistan. Higher Education Research \& Development, 36: 730-746. https://doi.org/10.1080/07294360.2016.1236782

[14] Saroia, A. I., \& Gao, S. (2018). Investigating university students' intention to use mobile learning management systems in Sweden. Innovations in Education and Teaching International, 1-12. https://doi.org/10.1080/14703297.2018.1557068.

[15] Habibi, A., Yusop, F, D., \& Rafiza, A. R. (2019). The dataset for validation of factors affecting pre-service teachers' use of ICT during teaching practices: Indonesian context. Data in Brief, 28. https://doi.org/10.1016/i.dib.2019.104875

[16] Behr, D. (2017). Assessing the use of back translation: The shortcomings of back translation as a quality testing method. International Journal of Social Research Methodology, 20(6): 573-584. https://doi.org/10.1080/13645579.2016.1252188

[17] Luschei, T. F. (2017). 20 Years of TIMSS: Lessons for Indonesia. Indonesian Research Journal in Education| IRJE|, 6-17. 
[18] Hair, J. F., Black, W. C., \& Babin, B. J. (2010). Multivariate data analysis. New Jersey, Pearson Prentice Hall.

[19] Ryan, G, W. (2004). Using a Word processor to tag and retrieve blocks of text. Field Methods, 16(1): 109-30. https://doi.org/10.1177/1525822x03261269

[20] Prasojo, L. D., Mukminin, A., Habibi, A., Marzulina, L., Muhammad, S., \& Harto, K. (2018). Learning to teach in a digital age: ICT integration and EFL student teachers' teaching practices. Teaching English with Technology, 18(3): 18-32.

\section{Authors}

Aman is an associate Professor of Universitas Negeri Yogyakarta, Faculty of education. Jl. Colombo No.1, Karang Malang, Caturtunggal, Kec. Depok, Kabupaten Sleman, Daerah Istimewa Yogyakarta 55281, Indonesia.

Lantip Diat Prasojo is a full Professor of educational technology at educational management study program of Universitas Negeri Yogyakarta. He is the head of Indonesian educational management teacher educators.

Muhammad Sofwan is a senior lecturer working at Universitas Jambi, Indonesia. Jl. Lintas Sumatera Jl. Jambi - Muara Bulian No.Km. 15, Mendalo Darat, Kec. Jambi Luar Kota, Kabupaten Muaro Jambi, Jambi 36122, Indonesia

Amirul Mukminin is a Faculty member at Faculty of Education/Graduate School, Jambi University, Indonesia. He holds a PhD from Florida State University, USA in Educational Leadership and Policy Studies and MS in educational sciences from Groningen University, the Netherlands.

Akhmad Habibi is an educational researcher working at Universitas Jambi, Indonesia. Focusing on statistics and education, he has published his works in many journals (e.g. Education and Information Technologies, Heliyon, Data in Brief, SageOpen, The Qualitative Report, Electronic Journal of e-Learning, Journal of Baltic of Educational Science, etc.). He is a reviewer for some reputable journals like Heliyon, IEEE Access, SageOpen, Accountability in Research, International Journal of Instruction, etc.

Lalu Nurul Yaqin is lecturer at Universitas Gunung Rinjani, No.KM 59, Jl. Raya Mataram - Labuhan Lombok, Anjani, Selong, Kabupaten Lombok Timur, Nusa Tenggara Bar. 83659, Indonesia.

Article submitted 2019-10-26. Resubmitted 2019-12-17. Final acceptance 2019-12-18. Final version published as submitted by the authors. 